\title{
Rediscovering the history of orthopedics
}

\author{
Maurilio Marcacci - Berardo Di Matteo • \\ Giuseppe Filardo $\cdot$ Vittorio Tarabella
}

Published online: 28 July 2013

(c) Springer-Verlag Berlin Heidelberg 2013

History is difficult to digest, particularly for physicians like us who are constantly pressed to deliver results, always committed to the everyday medical practice, and required to keep up to date with the most recent research. It is not surprising, then, that in recent years there has been a shortage of historical insight into indexed journals: where can we find the time to read papers not dealing with the progress of research or the latest updates in surgical procedures? Therefore, why care about finding space to publish manuscripts with different prerogatives?

Our profession is undergoing a process of strict sectionalization and superspecialization. Those of us working both in research and clinical practice know that in order to improve, we need to be in perpetual pursuit of new technological frontiers from the latest clinical studies. Together, focusing on the short-term future and our intense clinical routine often pushes us to forget how much ingenuity there is in our work, which is the reason we choose and come to love this career. Studying our history gives us the opportunity to remember how extraordinary the field of orthopedics is, how brilliant the inventions of our standard procedures are, and the meaning of our role in society. It brings us back to the original facts, events, and personalities of our past, the ones that founded and made modern orthopedics possible: the inventions, the revolutions in paradigms that were thought to be unchangeable. The American writer Robert Hanson Heinlein said: "Every-

M. Marcacci · B. Di Matteo $(\square)$ · G. Filardo · V. Tarabella Biomechanics Laboratory and II Orthopaedic Clinic, Rizzoli Orthopaedic Institute, Via di Barbiano n. 1/10, 40136 Bologna, Italy

e-mail: berardo.dimatteo@gmail.com thing is theoretically impossible, until it is done. One could write a history of science in reverse by assembling the solemn pronouncements of the highest authority about what could not be done and could never happen.' Realizing this, by becoming more attuned to the greatness of our own past, we can grow as people and professionals, and by promoting this intriguing connection, we can provide new perspectives and meanings to both younger researchers and experienced practitioners.

The usefulness of rediscovering history and its educational value has lately become increasingly recognized [1]. The full spectrum of topics that may be of interest is vast and layered, as is the depth of our tradition: bones and ligaments have been breaking since the beginning of humankind [2], and for sure there were orthopedic surgeons long before the word "orthopedic" came into common use. You may find inspiration in reading about the lives and career breakthroughs of orthopedic pioneers such as Ambrose Paré [3], John Rhea Barton [4], and Alessandro Codivilla [5], or about the "institutional fathers" of our discipline: Nicholas Andry, Jean-Andrè Venel, and John Ball Brown [6]. It might be inspiring to understand the challenge of being a physician in a time when medicine was seen as a whole without boundaries of experience or specialization [7], or even knowing how a specific surgical procedure [8] or technology [9] became established in current clinical practice, or learning how they were taught by masters [10] who believed in new methodologies. You might be surprised to learn that current tendencies and ways of understanding treatment in our field, such as the concept of restoring or repairing tissue instead of removing it, were seeded centuries ago [11].

It might seem commonplace to state that looking at the past is helpful to understanding and improving our present and future, but being commonplace does not make it 
worthless. Whatever whets your appetite in these papers, whether they are more in-depth studies [12] or even give you quicker insight, they will shine a light on the creativity and inventiveness of our rapidly evolving profession.

Younger orthopedists need to be encouraged by feeling they belong to a medical category and tradition of ingenuity and innovation; they must be driven by ideas, examples of creativity and determination, dedication to work, and thus to finding new solutions and new points of view so as not to get lost in data charts and clinical routines. They must be shown that our work is made both of inch-by-inch hardship and revolutionary thoughts. We therefore hope to share our enjoyment and renewal in rediscovering the roots of our profession and awareness of our role in the community, both as doctors and researchers. Therefore, both in digital and paper form, the journal Knee Surgery, Sports Traumatology, Arthroscopy (KSSTA) will begin an exploration of the history of orthopedics, a commendable effort to spread and show inside our craft the most visionary experiences and important events of our history, to retain the memory of our past, and, in doing so, shape us into better doctors.

Together with Professors Jon Karlsson and Renè Verdonk, we invite other research groups like ours to dedicate a little of their time to studying this "special" area of orthopedic research: all of you interested in this topic are welcome to contribute to this ambitious project-in which we firmly believe-so that KSSTA can be enriched not only by the latest findings in clinical trials but also by cultural findings from original inquiries focusing on the history of orthopedics.

\section{References}

1. Hernigou P, Pecina M (2013) History as a tool in orthopaedic education. Int Orthop 37:351-353

2. Donati D, Zolezzi C, Tomba P, Viganò A (2007) Bone grafting: historical and conceptual review, starting with an old manuscript by Vittorio Putti. Acta Orthop 78:19-25

3. Hernigou P (2013) Ambroise Paré's life (1510-1590): part I. Int Orthop 37:543-547

4. Di Matteo B, Tarabella V, Filardo G, Viganò A, Tomba P, Marcacci M (2013) John Rhea Barton: the birth of osteotomy. Knee Surg Sports Traumatol Arthrosc. doi:10.1007/s00167-0132387-1

5. Brand RA (2008) Advances in limb lengthening and reconstruction: Alessandro Codivilla, MD, 1861-1912. Clin Orthop Relat Res 466:2901-2902

6. Di Matteo B, Tarabella V, Filardo G, Tomba P, Viganò A, Marcacci M (2013) The "GENESIS" of modern orthopaedics: portraits of three illustrious pioneers. Int Orthop. doi:10.1007/ s00264-013-1936-z

7. Di Matteo B, Tarabella V, Filardo G, Viganò A, Tomba P, Marcacci M (2013) The traumatologist and the battlefield: the book that changed the history of traumatology. J Trauma Acute Care Surg 74:339-343

8. Smith JO, Wilson AJ, Thomas NP (2013) Osteotomy around the knee: evolution, principles and results. Knee Surg Sports Traumatol Arthrosc 21:3-22

9. Jackson RW (2010) A history of arthroscopy. Arthroscopy 26:91-103

10. Dejour DH (2013) The patellofemoral joint and its historical roots: the Lyon School of Knee Surgery. Knee Surg Sports Traumatol Arthrosc 21:1482-1494

11. Di Matteo B, Tarabella V, Filardo G, Viganò A, Tomba P, Marcacci M (2013) Thomas Annandale: the first meniscus repair. Knee Surg Sports Traumatol Arthrosc. doi:10.1007/s00167-013-2490-3

12. Schindler OS (2012) Surgery for anterior cruciate ligament deficiency: a historical perspective. Knee Surg Sports Traumatol Arthrosc 20:5-47 